\title{
Venovenous extracorporeal life support for posttraumatic respiratory distress syndrome in adults: the risk of major hemorrhages
}

Meng-Yu Wu' ${ }^{1}$, Pyng-Jing Lin ${ }^{1}$, Yuan-His Tseng ${ }^{1}$, Kuo-Chin Kao ${ }^{2,3}$, Hsuan-Ling Hsiao ${ }^{4}$ and Chung-Chi Huang ${ }^{2,3^{*}}$

\begin{abstract}
Background: The aim of this retrospective study is to investigate the therapeutic benefits and the bleeding risks of venovenous extracorporeal life support (W-ECLS) when used for adult posttraumatic respiratory distress syndrome (posttraumatic ARDS).

Materials and methods: Twenty adult trauma patients (median age: 38 years, median injury severity score: 35 ) treated with W-ECLS in a level I trauma center between January 2004 and June 2013 were enrolled in this study. The indication of $\mathrm{W}$-ECLS for posttraumatic ARDS was refractory hypoxemia $\left(\mathrm{P}_{\mathrm{a}} \mathrm{O}_{2} / \mathrm{F}_{\mathrm{i}} \mathrm{O}_{2}\right.$ ratio $\left.\leq 70 \mathrm{mmHg}\right)$ under advanced mechanical ventilation. To minimize potential complications, a protocol-guided W-ECLS was adopted.

Results: Sixteen patients were weaned off W-ECLS, and of these patients fourteen survived. Medians of the trauma-to-ECLS time, the pre-ECLS mechanical ventilation, and the ECLS duration in all patients were 64, 45, and 144 hours respectively. The median $\mathrm{P}_{\mathrm{a}} \mathrm{O}_{2} / \mathrm{F}_{i} \mathrm{O}_{2}$ ratio was improved significantly soon after $\mathrm{W}$-ECLS, from 56 to $106 \mathrm{mmHg}(p<0.001)$. However, seven major hemorrhages occurred during $\mathrm{W}$-ECLS, of which three were lethal. The multivariate analysis revealed that the occurrence of major hemorrhages during W-ECLS was independently related to the trauma-to-ECLS time $<24$ hours (OR: 20; $p=0.02 ; 95 \%$ Cl: 2-239; c-index: 0.81).

Conclusions: Despite an effective respiratory support, W-ECLS should be cautiously administered to patients who develop advanced ARDS soon after major trauma.

Keywords: Extracorporeal life support, Extracorporeal membrane oxygenation, Posttraumatic acute respiratory distress syndrome, Blunt chest trauma, Heparin-minimized strategy
\end{abstract}

\section{Introduction}

Acute respiratory distress syndrome (ARDS) is a potentially lethal problem in trauma patients [1,2]. Based on the Berlin definition [3], the typical presentation of posttraumatic ARDS is a hypoxemic status [an arterial oxygen tension $\left(\mathrm{P}_{\mathrm{a}} \mathrm{O}_{2}\right)$ /fraction of inspired oxygen $\left(\mathrm{FiO}_{2}\right)$ ratio $\leq 300 \mathrm{mmHg}$ with a positive end-expiratory pressure (PEEP) $\geq 5 \mathrm{cmH}_{2} \mathrm{O}$ ] that is accompanied with bilateral pulmonary opacities, and occurs shortly after trauma. The common predisposing

\footnotetext{
* Correspondence: david3627@gmail.com

${ }^{2}$ Department of Thoracic Medicine, Chang Gung Memorial Hospital and Chang Gung University, 5, Fushing Street, Gueishan Shiang, Taoyuan 333, Taiwan

${ }^{3}$ Department of Respiratory Therapy, Chang Gung Memorial Hospital and Chang Gung University, 5, Fushing Street, Gueishan Shiang, Taoyuan 333, Taiwan

Full list of author information is available at the end of the article
}

factors of posttraumatic ARDS are blunt thoracic injuries, traumatic shock requiring massive blood transfusion, and an injury severity score (ISS) $\geq 25$ [2]. Similar to ARDS caused by nontraumatic etiologies, posttraumatic ARDS is primarily treated with mechanical ventilation. To reduce the injurious effects of cyclical inflation and deflation on the already injured lungs during positive pressure ventilation, lung-protective ventilation is preferred among ARDS patients, using low tidal-volumes $(\leq 6 \mathrm{~mL} / \mathrm{kg} / \mathrm{min})$ and optimal PEEPs to achieve an inspiratory plateau pressure $\left(\mathrm{P}_{\text {plt }}\right) \leq 30 \mathrm{cmH}_{2} \mathrm{O}[4,5]$. However increases in $\mathrm{FiO}_{2}$, PEEP, and $\mathrm{P}_{\text {plt }}$ may be unavoidable when an acceptable arterial oxygenation cannot be maintained. The hyperinflatedhyperoxic ventilation may exacerbate pulmonary shunting and induce a repeated mechanical-biological trauma [6]. This ventilator-induced lung injury may initiate a vicious 
cycle that leads to severe ARDS $\left(\mathrm{P}_{\mathrm{a}} \mathrm{O}_{2} / \mathrm{FiO}_{2}\right.$ ratio $\leq$ $100 \mathrm{mmHg}$ ) with multiple organ dysfunctions [7]. Venovenous extracorporeal life support (VV-ECLS) may break this vicious cycle by conducting a prepulmonary blood gas exchange to share the workload with native lung, which enables physicians to continue lung-protective ventilation [8]. Nevertheless, because of its inherent thrombogenicity owing to the blood-surface interaction [9], VV-ECLS requires systemic heparinization and involves a $40 \%$ risk of hemorrhage at intracranial, surgical, and cannulation sites [10]. This risk may increase when VV-ECLS is administrated to patients who have just sustained major trauma and damage-control interventions. These patients tend to have the trauma-induced coagulopathy (TIC) [11] and may be vulnerable to heparinization. To evaluate the therapeutic benefits and bleeding risks of VV-ECLS when used for posttraumatic ARDS, nine years of experience with this therapy was reviewed.

\section{Materials and methods Study population}

From January 2004 to June 2013, a total of 561 patients received ECLS for hemodynamic (venoarterial mode; $\mathrm{n}=$ 437) or pulmonary (VV mode; $n=124$ ) support at Chang Gung Memorial Hospital. Among the 124 patients, 20 adults had posttraumatic ARDS and were enrolled in this retrospective study. The institutional review board of the hospital approved the protocol (CGMF IRB no. $102-4437 \mathrm{~B})$ and waived the necessity of individual patient consent.

Therapeutic protocol: conventional mechanical ventilation The definition of posttraumatic ARDS was based on the Berlin definition [3]. Conventional mechanical ventilation was used as the primary respiratory support for posttraumatic ARDS and a lung-protective strategy was adopted under paralytic sedation. The protocol of conventional mechanical ventilation for posttraumatic ARDS was demonstrated in our previous report [12] and showed in Additional file 1. When conventional mechanical ventilation alone was thought insufficient for an adequate arterial oxygenation (often a $\mathrm{P}_{\mathrm{a}} \mathrm{O}_{2} / \mathrm{FiO}_{2}$ ratio $<$ $70 \mathrm{mmHg}$ with a $\mathrm{FiO}_{2} \geq 0.8$ ), VV-ECLS was administered. The exclusion criteria of VV-ECLS were (1) an uncontrolled hemorrhagic shock; (2) an identified acute heart failure; or (3) a severe traumatic brain injury. A whole body computed tomography was suggested to all candidates to exclude undetected internal hemorrhages before the administration of VV-ECLS.

\section{Implantation of VV-ECLS}

As reported previously [13], we used the Capiox emergent bypass system (Terumo Inc., Tokyo, Japan) with a heparin-coated inner surface as our ECLS device. Since a double lumen catheter was not available during the period of study, two wire-wound polyurethane vascular cannulae (DLP Medtronic, Minneapolis, MN, USA; inflow: 19-23 French, outflow: 17-21 French) were used to established the femoral (in)-jugular (out) VV-ECLS via percutaneous cannulation. The ECLS gas flow rate was initially set high $(10 \mathrm{~L} / \mathrm{min}$, pure oxygen), and the blood pump speed was gradually increased to achieve a pulse oximetry-detected oxyhemoglobin saturation $\left(\mathrm{S}_{\mathrm{p}} \mathrm{O}_{2}\right) \geq$ $90 \%$. If necessary, a modest volume replacement (preferably packed red blood cell) was used to improve an unsteady ECLS blood flow. The positions of the cannula tips were confirmed with a chest-abdominal radiograph in order to prevent a substantial recirculation.

\section{Therapeutic Protocol of VV-ECLS in posttraumatic ARDS}

Figure 1 illustrates our VV-ECLS protocol for posttraumatic ARDS. Anticoagulation, oxygenation, and ventilation were three highlighted points. Before implantation, the ECLS specialists must evaluate the risks and benefits of administering a fully heparinized (heparin-titrated) VV-ECLS to the trauma patient. Based on our experience of postcardiotomy ECLS [14], we routinely administer the heparin-minimized ECLS to patients who require ECLS within 24 hours after major surgeries or trauma [15], since these patients are at high risk for consumption coagulopathies. TIC is a consumption coagulopathy specific to trauma patients, and is defined as a hypocoagulable state [prothrombin time (PT) - international normalized ratio (INR) $\geq 1.2$ or the activated partial thromboplastin time (aPTT) $\geq 35$ seconds] presented soon after trauma [16,17]. The active clotting time (ACT) and aPTT were checked as needed, at least every 6 hour in the first day of VVECLS. In heparin-titrated ECLS, the therapeutic range of the ACT/aPTT value was $160-180 / 40-55$ seconds, and heparin was administered intravenously when the aPTT value dropped below 40 seconds. Patients on the heparinminimized ECLS received no exogenous heparinization. The heparin-minimized ECLS maintained a high blood flow rate $(>3 \mathrm{~L} / \mathrm{min})$ and was switched to the heparintitrated mode after 48 hours to reduce the possibility of thromboembolism. To achieve acceptable oxygenation and to reduce the bleeding risk, hemaglobin and platelet count were also checked daily to maintain a level more than $10 \mathrm{~g} / \mathrm{dL}$ and 80 billion/L, respectively. Coagulation factor transfusion was seldom needed in patients without hemorrhage. In patients with hemorrhages, withholding heparin plus blood transfusion (RBC: plasma: platelet about 1:1:3) was the first step to achieve hemostasis on ECLS. Endoscopic, angiographic or surgical hemostasis was launched with low threshold once the conservative treatment failed or was impossible to stablize the hemorrhage. When an obvious anisocoria (a diameter difference > $2 \mathrm{~mm}$ ) was detected, a brain computed tomography was 


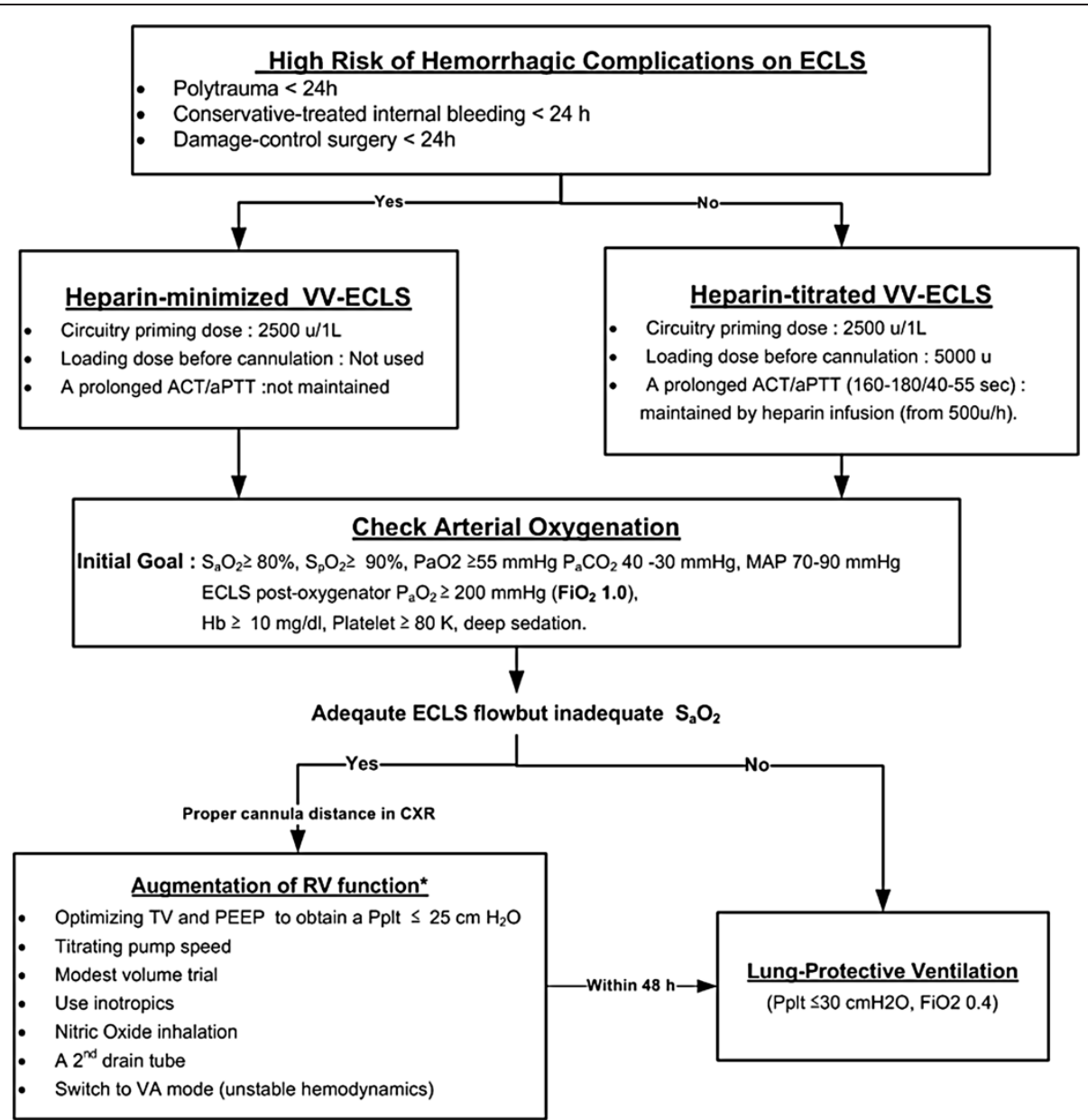

Figure 1 The therapeutic protocol of venovenous extracorporeal life support in patients with posttraumatic acute respiratory distress syndrome. ACT: Active clotting time. aPTT: Activated partial thromboplastin time. PEEP: Positive end-expiratory pressure. $\mathrm{S}_{\mathrm{p}} \mathrm{O}_{2}$ : Pulse oximetry-detected oxyhemoglobin saturation. $\mathrm{P}_{\mathrm{a}} \mathrm{O}_{2}$ : Arterial oxygen tension. $\mathrm{P}_{\mathrm{a}} \mathrm{CO}_{2}$ : Arterial carbon dioxide tension. MAP: Mean arterial pressure. $\mathrm{Hb}$ : Hemoglobin. $\mathrm{FiO}_{2}$ : The fraction of inspired oxygen. TV3: Tidal volume. Pplt: Inspiratory plateau pressure.

immediately performed to assess the possibility of ICHs. VV-ECLS was withdrawn (or rapidly weaned) after obtaining the family's permission when a major ICH was identified. The choice whether to perform a surgical decompression depended on the opinion of the consulting neurosurgeon.

The adequacy of oxygenation during VV-ECLS was checked by repeated arterial blood gas samplings, at least every 6 hours during the first day. With an improvement of $\mathrm{S}_{\mathrm{p}} \mathrm{O}_{2}$, the lung-protective ventilation was continued with a decreased $\mathrm{FiO}_{2}$, respiratory rate, and $\mathrm{P}_{\text {plt }}$. However attempts to step-down the $\mathrm{FiO}_{2}$ may be hindered by an unsatisfactory $\mathrm{S}_{\mathrm{p}} \mathrm{O}_{2}$ level in spite of a well-functioning VV-ECLS. A substantial recirculation of the outflow (oxygenated) blood of VV-ECLS was often found in this scenario and needed to be corrected quickly [18]. Figure 1 also outlines common methods of reducing the recirculation during VV-ECLS. After optimizing the oxygenation, it was critical to remove the excessive lung water with diuretics or continuous venovenous hemofiltration in order to improve the pulmonary compliance [19]. Weaning from the ECLS was tried once significant pulmonary improvements were shown. The pump flow was tapered to $2.0 \mathrm{~L} / \mathrm{min}$ then the $\mathrm{FiO}_{2}$ of the ECLS gas flow was turned to 0.21 . Decannulation was performed after 4 to 6 hours if the patient remained stable. The weaning process would be stopped if (1) hemodynamic instability, or (2) a $\mathrm{P}_{\mathrm{a}} \mathrm{O}_{2} / \mathrm{FiO}_{2}$ ratio $<$ $100 \mathrm{mmHg}$ or $\mathrm{P}_{\mathrm{a}} \mathrm{CO}_{2} \geq 60 \mathrm{mmHg}$ under lung protective ventilation with a maximal $\mathrm{FiO}_{2}$ of 0.6 .

\section{Statistical analysis}

Statistical analyses were performed using SPSS for Windows (Version 15.0, SPSS, Inc., IL, USA). Because the dataset was small, nonparametric methods including the MannWhitney $U$ or Wilcoxon signed ranks tests was used to 
conduct univariate comparisons of the independent or paired continuous variables. The Chi-square or Fisher's exact test was used to compare the categorical variables. The level of statistical significance was set at $p<0.05$.
Continuous variables with a $p<0.05$ were dichotomized on the basis of cut-off values [14]. The cut-off values were determined by the receiver operating characteristic curve (ROC) analysis. These dichotomized risk factors were

Table 1 Summary of the characteristics of trauma, types of damage-control interventions, and outcomes

\begin{tabular}{|c|c|c|c|c|c|c|c|}
\hline \multirow[t]{2}{*}{ No } & \multirow{2}{*}{$\begin{array}{l}\text { Age } \\
\text { (year) }\end{array}$} & \multirow[t]{2}{*}{ Mechanism of trauma } & \multirow[t]{2}{*}{ ISS } & \multicolumn{2}{|c|}{ Pre-ECLS management } & \multirow{2}{*}{$\begin{array}{l}\text { Trauma } \\
\text { to ECLS } \\
\text { (hour) }\end{array}$} & \multirow{2}{*}{$\begin{array}{l}\text { Outcome (ECLS } \\
\text { hour) }\end{array}$} \\
\hline & & & & $\begin{array}{l}\text { MV } \\
\text { hour }\end{array}$ & Damage control surgery/TAE & & \\
\hline 1 & 53 & Car-pedestriant accident & 20 & 4 & No & 5 & Survived (69) \\
\hline 2 & 29 & Motorbike accident & 17 & 6 & No & 7 & $\begin{array}{l}\text { Withdrawn- } \\
\text { and-survived (61) }\end{array}$ \\
\hline 3 & 33 & Motorbike accident & 29 & 5 & Thoracotomy: RML-RLL bilobectomy, pericardiotomy & 9 & Survived (187) \\
\hline 4 & 38 & Motorbike accident & 50 & 8 & No & 10 & $\begin{array}{l}\text { Weaned-and-survived } \\
\text { (145) }\end{array}$ \\
\hline 5 & 59 & Car accident & 75 & 9 & $\begin{array}{l}\text { Pericardiocentesis and subxiphoid incision } \\
\text { to release cardiac tamponade }\end{array}$ & 11 & Survived (75) \\
\hline \multirow[t]{2}{*}{6} & \multirow[t]{2}{*}{23} & \multirow[t]{2}{*}{ Accidental fall } & \multirow[t]{2}{*}{75} & \multirow[t]{2}{*}{9} & Thoracotomy: Repair RML/RLL lacerations & \multirow[t]{2}{*}{14} & \multirow{2}{*}{$\begin{array}{l}\text { Withdrawn-and-dead } \\
\text { (40) }\end{array}$} \\
\hline & & & & & $\begin{array}{l}\text { Laparotomy: Ligation of right hepatic artery with perihepatic } \\
\text { packing }\end{array}$ & & \\
\hline 7 & 49 & $\begin{array}{l}\text { Trunk-pedestriant } \\
\text { accident }\end{array}$ & 41 & 14 & $\begin{array}{l}\text { TAE for retroperitoneal hemorrhage, external } \\
\text { fixation of pelvic fracture }\end{array}$ & 16 & Survived (222) \\
\hline 8 & 43 & Motorbike accident & 29 & 4 & No & 21 & Survived (77) \\
\hline \multirow[t]{2}{*}{9} & \multirow[t]{2}{*}{20} & \multirow[t]{2}{*}{ Motorbike accident } & \multirow[t]{2}{*}{75} & \multirow[t]{2}{*}{21} & TAE for grade 4 hepatic laceration. & \multirow[t]{2}{*}{23} & \multirow[t]{2}{*}{ Dead-on-ECLS (24) } \\
\hline & & & & & $\begin{array}{l}\text { Laparotomy: Ligation of right hepatic artery and } \\
\text { right portal vein with perihepatic packing }\end{array}$ & & \\
\hline \multirow[t]{2}{*}{10} & \multirow[t]{2}{*}{57} & \multirow[t]{2}{*}{ Car accident } & \multirow[t]{2}{*}{75} & \multirow[t]{2}{*}{49} & $\begin{array}{l}\text { TAE for retroperitoneal hemorrhage, external fixation } \\
\text { of pelvic fracture. }\end{array}$ & \multirow[t]{2}{*}{52} & \multirow[t]{2}{*}{ Dead-on-ECLS (423) } \\
\hline & & & & & $\begin{array}{l}\text { Laparotomy: Resect terminal ileum and right colon } \\
\text { with end-ileostomy for bowel perforation }\end{array}$ & & \\
\hline 11 & 37 & $\begin{array}{l}\text { Accidental fall with chest } \\
\text { penetrating injury }\end{array}$ & 22 & 74 & $\begin{array}{l}\text { Laparotomy: Repair gastric and diaphragmatic } \\
\text { perforation, repair spleen avulsion }\end{array}$ & 76 & Survived (66) \\
\hline 12 & 61 & Motorbike accident & 43 & 91 & Laparotomy: Repair small bowel perforation & 100 & Survived (143) \\
\hline 13 & 32 & Motorbike accident & 29 & 126 & Internal fixation of right proximal femoral fracture & 138 & Dead-on-ECLS (1030) \\
\hline \multirow[t]{2}{*}{14} & \multirow[t]{2}{*}{28} & Car accident & 43 & 143 & TAE for grade 3 hepatic laceration & 175 & Survived (94) \\
\hline & & & & & Laparotomy: Repair mesocolonic laceration & & \\
\hline 15 & 72 & Motorbike accident & 18 & 227 & Thoracoscopy for empyema evacuation & 248 & Dead-on-ECLS (111) \\
\hline 16 & 56 & Motorbike accident & 10 & 150 & No & 295 & Survived (517) \\
\hline 17 & 25 & Trunk-pedestriant & 41 & 365 & TAE for grade 3 hepatic laceration & 384 & Survived (456) \\
\hline & & & & & $\begin{array}{l}\text { Thoracotomy: RML -RLL bilobectomy and } \\
\text { bronchoplasty }\end{array}$ & & \\
\hline & & & & & Exploratory laparotomy & & \\
\hline 18 & 27 & Motorbike accident & 50 & 174 & TAE for grade 5 hepatic laceration & 574 & Weaned-but-Dead (352) \\
\hline & & & & & $\begin{array}{l}\text { Laparoscopy for persistent bile leak and } \\
\text { intra-abdominal abscess }\end{array}$ & & \\
\hline & & & & & Thoracotomy: Descending aortic replacement & & \\
\hline 19 & 27 & Compression injury & 25 & 40 & Laparotomy: Cystorrhaphy & 115 & Survived (161) \\
\hline 20 & 58 & Accidental fall & 17 & 310 & TAE for grade 4 renal laceration & 334 & Survived (169) \\
\hline
\end{tabular}

ECLS: Extracorporeal life support.

MV hour: Mechanical ventilation hour before and extended to ECLS without interruption. TAE: Transcatheter arterial embolization.

CA: Cardiac arrest. RML: Right middle lobe of lung, RLL: Right lower lobe of lung. 
tested by the multivariate logistic regression analysis to identify independent predictors of in-hospital mortality and occurrence of major hemorrhages.

\section{Results}

\section{Demographics}

Table 1 summarizes the trauma characteristics, preECLS managements, and outcomes of the twenty patients. A combination of high-grade thoracoabdominal injuries were common and resulted in a high median ISS (35; IQR: 21-50). The median durations of the preECLS mechanical ventilation and the trauma-to-ECLS time were 45 (IQR: 8-148) hours and 64 (IQR: 12-230) hours, respectively. Fifteen patients received damagecontrol interventions, including thoracotomy (including subxiphoid incision; $\mathrm{n}=7$ ), laparotomy $(\mathrm{n}=7)$, or transcatheter arterial embolization $(n=7)$ before VV-ECLS. Four patients were diagnosed with minor intracranial hemorrhages (ICH in Cases 4 and 14, SAH in Cases 12 and 15) before VV-ECLS. Sixteen patients were weaned off VV-ECLS and fourteen survived. The six nonsurvivors died of sepsis $(n=3)$ or hemorrhagic complications during ECLS $(n=3)$. Table 2 lists the results of univariate comparisons of clinical parameters between different patient groups. Despite there being no independent risk factor of in-hospital mortality identified, a trauma-to-ECLS time $\leq 15$ hours [Sensitivity (Sn): 71\%; Specificity (Sp): 92\%; Positive Predictive Value (PPV): $83 \%$; Negative Predictive Value (NPV): $86 \%$; area under ROC curve (AUROC): 0.82 ; $p=0.02]$ was found to be the independent predictor of hemorrhage during VV-ECLS [odd ratio (OR): $30, p=0.01$, 95\% confidence intervals (CI): 2-441]. For practical purposes, we also tested the predictive power of a traumato-ECLS time $\leq 24$ hours. Acceptable predictive power was also obtained in this cut-off point (Sn: 86\%; Sp: 77\%; PPV: 67\%, NPV: 91\%, AUROC: 0.81; $p=0.02)$. The OR, $p$ value, and $95 \% \mathrm{CI}$ at this point were $20,0.02$, and 2-239, respectively.

Table 2 Demographic and clinical data

\begin{tabular}{|c|c|c|c|c|c|c|}
\hline Variable & $\begin{array}{l}\text { Survivors } \\
(n=14)\end{array}$ & $\begin{array}{l}\text { Non-survivors } \\
(\mathrm{n}=6)\end{array}$ & $p$ & $\begin{array}{l}\text { Patient with hemorrhagic } \\
\text { complication }(n=7)\end{array}$ & $\begin{array}{l}\text { Patient without hemorrhage } \\
\text { complications }(n=13)\end{array}$ & $p$ \\
\hline Age (years) & $41(29-57)$ & $30(22-61)$ & 0.35 & $33(23-53)$ & $43(28-58)$ & 0.49 \\
\hline Injury severity score & $29(19-43)$ & $63(26-75)$ & 0.09 & $29(18-75)$ & $41(24-47)$ & 1.0 \\
\hline Pre-ECLS CPR (n) & 1 & 3 & 0.06 & 2 & 2 & 0.59 \\
\hline Pre-ECLS ICH (n) & 2 & 2 & 0.55 & 2 & 2 & 0.59 \\
\hline Trauma-to-ECLS hour & $49(10-205)$ & $95(21-329)$ & 0.35 & $10(7-23)$ & $115(37-315)$ & $0.008^{*}$ \\
\hline Trauma-to-ECLS $<24$ hours (n) & 2 & 7 & 0.64 & 6 & 3 & $0.02^{*}$ \\
\hline Pre-ECLS intubation hour & $27(6-145)$ & $88(18-187)$ & 0.31 & $8(5-21)$ & $91(27-162)$ & $0.04^{*}$ \\
\hline Pre-ECLS RBC transfusion $^{\dagger}(\mathrm{u})$ & $1(0-4)$ & $10(1-18)$ & 0.34 & $6(3-17)$ & $1(0-3)$ & $0.05^{*}$ \\
\hline Pre-ECLS platelet transfusion $(u)$ & 0 & $6(0-39)$ & 0.1 & $0(0-18)$ & 0 & 0.58 \\
\hline Pre-ECLS plasma transfusion ${ }^{\ddagger}(\mathrm{u})$ & $5(3-16)$ & $11(0-17)$ & 0.18 & $5(3-16)$ & $2(0-6)$ & $0.05^{*}$ \\
\hline Pre-ECLS TIC & 9 & 6 & 0.26 & 6 & 9 & 0.61 \\
\hline Heparin-minimized ECLS (n) & 7 & 4 & 0.64 & 7 & 4 & $0.005^{*}$ \\
\hline ECLS pump flow (L/min) & $4(3.6-4.6)$ & $3.7(3.4-4)$ & 0.27 & $4.1(3.3-4.3)$ & $3.6(3.5-4.6)$ & 0.7 \\
\hline $1^{\text {st }}$ day $\mathrm{RBC}$ transfusion ${ }^{\dagger}(\mathrm{u})$ & $1(1-10)$ & $7(3-13)$ & 0.16 & $10(3-14)$ & $1(1-6)$ & $0.007^{*}$ \\
\hline $1^{\text {st }}$ day Platelet transfusion $(\mathrm{u})$ & $0(0-24)$ & $12(12-24)$ & 1.0 & $24(12-24)$ & $0(0-12)$ & $0.03^{*}$ \\
\hline $1^{\text {st }}$ day Plasma transfusion ${ }^{\ddagger}(\mathrm{u})$ & $11(5-22)$ & $10(0-24)$ & 0.26 & $11(5-22)$ & $0(0-7)$ & $0.05^{*}$ \\
\hline CVVH on ECLS (n) & 3 & 4 & 0.12 & 1 & 6 & 0.33 \\
\hline Hemorrhagic complications (n) & 4 & 3 & 0.61 & - & - & - \\
\hline Weaning-off ECLS (n) & 14 & 2 & $0.003^{*}$ & 5 & 11 & 0.59 \\
\hline ECLS hour & $144(74-196)$ & $232(36-575)$ & 0.9 & $69(40-145)$ & $169(86-440)$ & $0.02^{*}$ \\
\hline Post-ECLS intubation hour & $231(61-476)$ & - & - & $72(0-363)$ & $111(23-427)$ & 0.7 \\
\hline Tracheostomy (n) & 7 & 1 & 0.33 & 2 & 6 & 0.64 \\
\hline Hospital days & $69(27-81)$ & $32(4-46)$ & $0.04^{*}$ & $45(5-76)$ & $45(27-78)$ & 0.49 \\
\hline
\end{tabular}

Numerical variable is presented as median and interquartile range (IQR).

ECLS: Extracorporeal life support. CPR: Cardiopulmonary resuscitation. ICH: Intracranial hemorrhage. Trauma-to-ECLS hour: The time interval between trauma to the initiation of ECLS. ${ }^{\dagger} \mathrm{RBC}$ transfusion includes the amount of whole blood and packed red cell concentrate. ${ }^{\ddagger}$ Plasma transfusion includes the amount of whole blood, frozen fresh plasma and cryoprecipitate. TIC: Trauma induced coagulopathy (INR $>1.3$ or aPTT $>35$ seconds). CVVH: Continuous venovenous hemofiltration. ${ }^{*} p<0.05$. 
Table 3 Laboratory data associated with gas exchange and coagulation

\begin{tabular}{|c|c|c|c|c|c|c|}
\hline Variable & $\begin{array}{l}\text { Survivors } \\
(n=14)\end{array}$ & $\begin{array}{l}\text { Non-survivors } \\
(\mathrm{n}=6)\end{array}$ & $p$ & $\begin{array}{l}\text { Patient with hemorrhagic } \\
\text { complication }(n=7)\end{array}$ & $\begin{array}{l}\text { Patient without hemorrhage } \\
\text { complications }(n=13)\end{array}$ & $p$ \\
\hline \multicolumn{7}{|l|}{ Pre-ECLS data } \\
\hline $\mathrm{PaO}_{2}(\mathrm{mmHg})$ & $56(48-73)$ & $55(42-67)$ & 0.55 & $53(42-66)$ & $58(49-69)$ & 0.59 \\
\hline $\mathrm{PaO}_{2} / \mathrm{FiO}_{2}$ ratio $(\mathrm{mmHg})$ & $56(48-73)$ & $57(42-68)$ & 0.66 & $53(42-66)$ & $58(49-70)$ & 0.7 \\
\hline $\mathrm{PaCO}_{2}(\mathrm{mmHg})$ & $61(47-89)$ & $52(41-76)$ & 0.64 & $49(40-78)$ & $52(49-91)$ & 1.0 \\
\hline Hemoglobin (g/dL) & $11(10-13)$ & $9(8-11)$ & 0.06 & $10(9-15)$ & $11(9-12)$ & 0.64 \\
\hline Platelet count $\left(\times 10^{9} / \mathrm{L}\right)$ & $164(90-193)$ & $88(51-34)$ & 0.11 & $172(107-183)$ & $115(67-193)$ & 0.76 \\
\hline INR of Prothrombin Time > 1.2 & 7 & 6 & $0.05^{*}$ & 5 & 8 & 1.0 \\
\hline aPTT > 35 (seconds) & 7 & 3 & 1.0 & 5 & 5 & 0.35 \\
\hline \multicolumn{7}{|l|}{ Data collected on ECLS at 1 hour } \\
\hline $\mathrm{PaO}_{2} / \mathrm{FiO}_{2}$ ratio $(\mathrm{mmHg})$ & $108(65-103)$ & $103(71-151)$ & 0.84 & $99(166-146)$ & $110(74-171)$ & 0.54 \\
\hline $\mathrm{PaCO}_{2}(\mathrm{mmHg})$ & $37(30-46)$ & $39(31-45)$ & 0.46 & $42(35-44)$ & $35(27-48)$ & 1.0 \\
\hline Hemoglobin g/dL) & $10(9-11)$ & $10(9-14)$ & 0.72 & $10(8-12)$ & $10(9-11)$ & 0.76 \\
\hline Platelet count $\left(\times 10^{9} / \mathrm{L}\right)$ & $98(65-153)$ & $100(45-134)$ & 0.72 & $99(31-142)$ & $100(64-160)$ & 0.54 \\
\hline INR of Prothrombin Time $>12^{\dagger}$ & 2 & 1 & 1.0 & 3 & 0 & $0.03^{*}$ \\
\hline $\mathrm{aPTT}>120^{\dagger}$ (seconds) & 10 & 6 & 0.27 & 6 & 10 & 1.0 \\
\hline \multicolumn{7}{|l|}{ at24 hour } \\
\hline $\mathrm{PaO}_{2} / \mathrm{FiO}_{2}$ ratio $(\mathrm{mmHg})$ & $190(100-246)$ & $93(86-262)$ & 0.44 & $98(86-238)$ & 180 (96-252) & 0.59 \\
\hline Hemoglobin (g/dL) & $10(9-11)$ & $10(9-12)$ & 0.6 & $10(8.8-12)$ & $10(9-11)$ & 0.82 \\
\hline Platelet count $\left(\times 10^{9} / \mathrm{L}\right)$ & $99(63-139)$ & $76(62-92)$ & 0.18 & $75(62-93)$ & $96(73-131)$ & 0.18 \\
\hline \multicolumn{7}{|l|}{ Before ECLS weaning } \\
\hline $\mathrm{PaO}_{2} / \mathrm{FiO}_{2}$ ratio $(\mathrm{mmHg})$ & $261(186-338)$ & - & - & $229(135-256)$ & $288(178-343)$ & 0.18 \\
\hline
\end{tabular}

Numerical variable is presented as median and interquartile range (IQR).

ECLS: Extracorporeal life support. $\mathbf{P a O}_{2} / \mathbf{F i O}_{2}$ ratio: The arterial oxygen tension $\left(\mathbf{P a O}_{2}\right)$ divided by the fraction of inspired oxygen (FiO $)$. INR: International normalized ratio. aPTT: Activated partial thromboplastin time. TIC: Trauma induced coagulopathy (INR $>1.3$ or aPTT $>>35$ ). ${ }^{*} p<0.05$. ${ }^{\dagger}$ The maximum of the detectable values.

\section{Improvements of arterial gas exchange}

A series of changes in $\mathrm{P}_{\mathrm{a}} \mathrm{O}_{2} / \mathrm{FiO}_{2}$ ratio during VV-ECLS between different patient groups was demonstrated in Table 3. An improved oxygenation was showed in all patients soon after the administration of VV-ECLS. After testing by the Wilcoxon signed ranks test, the increase of $\mathrm{P}_{\mathrm{a}} \mathrm{O}_{2} / \mathrm{FiO}_{2}$ ratio was significant in survivors $(p=0.004)$, non-survivors $(p=0.03)$, patients with hemorrhages $(p=0.003)$, and patients without hemorrhages $(p=0.005)$. However, only the survivors showed a continuous increase in $\mathrm{P}_{\mathrm{a}} \mathrm{O}_{2} / \mathrm{FiO}_{2}$ ratio in the first day of VV-ECLS $(p=0.01)$.

\section{The Incidence of Hemorrhaging during ECLS}

Eleven patients (Cases 1-10 and Case 15 for just receiving surgery for empyema) fulfilled the criteria and received heparin-minimized VV-ECLS for 48 hours. Seven patients

Table 4 Management of Hemorrhagic Complications on venovenous extracorporeal life support

\begin{tabular}{llll}
\hline Case & Clinical presentations (Hours after ECLS initiation) & Hemorrhagic site & Intervention on ECLS (Outcome) \\
\hline $\mathbf{1}$ & Hemorrhaging from the open fracture wound of sternum (2) & Fractured sternum & Sternotomy (Survived) \\
$\mathbf{2}$ & Anisocoria (61) & Multiple intracranial hemorrhages & Craniotomy (Survived) \\
$\mathbf{3}$ & Abdominal compartment syndrome $\left(I \mathrm{AP}{ }^{*}>30 \mathrm{~cm} \mathrm{H} \mathrm{H}_{2} \mathrm{O}\right)(12)$ & The conservatively-treated liver laceration & Peritoneal drainage (Survived) \\
$\mathbf{4}$ & Anisocoria (71) & Intraventricular hemorrhage & No (Survived) \\
$\mathbf{6}$ & Hemorrhaging from the decompressive laparotomy (12) & The packed liver laceration & Laparotomy (Dead) \\
& Anisocoria (40) & Multiple Intracranial hemorrhages. & No (Dead) \\
$\mathbf{1 5}$ & Hemorrhaging from the decompressive laparotomy (4) & The packed liver laceration & Thoracotomy (Dead) \\
\hline
\end{tabular}

*IAP: Intra-abdominal pressure. 
(six with TIC) had major hemorrhages during VV-ECLS, after a median ECLS duration of 12 (4-61) hours. All of the seven patients received heparin-minimized VV-ECLS as a prophylactic measure. The clinical presentations and management of the seven hemorrhagic complications are summarized in Table 4. A series of changes in coagulation profiles during VV-ECLS between different patient groups was also demonstrated in Table 3. To investigate the response of the patients' coagulation system to different ECLS strategies, aPTT data collected during the first day of VV-ECLS are presented as box plots in Figure 2.

\section{Discussion}

This study aimed to investigate the therapeutic benefits and the safety of VV-ECLS when used for adult posttraumatic ARDS, since the ECLS-associated coagulopathy may induce severe consequences in trauma patients. As seen in previous reports [20,21] and the current study, VV-ECLS is an efficient device to improve the blood gas exchange and may achieve a survival rate of more than $70 \%$ in adult patients with severe posttraumatic ARDS. The incidence of major hemorrhages during VV-ECLS is quite low in patients receiving VV-ECLS after several days
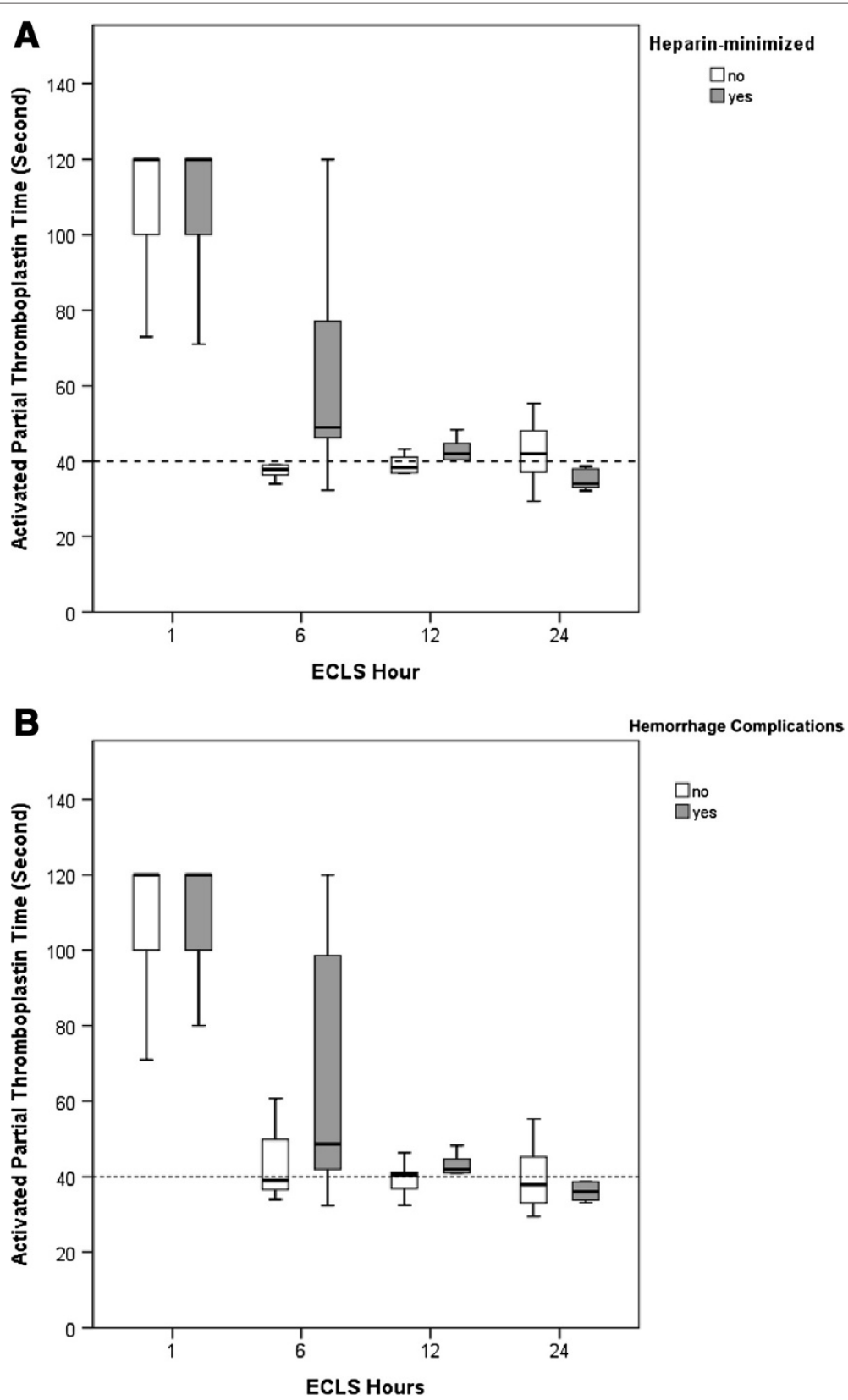

Figure $\mathbf{2}$ The time courses of the activated partial thromboplastin time during the first $\mathbf{2 4}$ hours of venovenous extracorporeal life support. Median with $25^{\text {th }}$ to $75^{\text {th }}$ interquatile range. ${ }^{*}$ The upper limit of detectable value of aPTT is 120 seconds. 
of trauma, as seen in patients supported for non-traumatic ARDS [10]. According to a recent study reported by Ried et al. [20], the incidence of major hemorrhages during extracorporeal lung support ( $\mathrm{n}=52 ; 26$ used VV-ECLS) is only $4 \%(n=2)$ in patients with a median trauma-to-ECLS time of 4.5 days. However, the therapeutic challenge here is administering VV-ECLS to patients at high risk for TIC. Despite being guided by a comprehensive protocol, the current study still yielded an incidence of major hemorrhages of $35 \%(\mathrm{n}=7)$ in 20 patients with a median trauma-to-ECLS time of 64 hours ( 2.7 days). The median trauma-to-ECLS time was only 10 hours in the group of hemorrhage. To explain the high incidence of major hemorrhages, we analyzed the changes of blood coagulability during VV-ECLS in order to evaluate the interaction between TIC and ECLS-associated coagulopathy. Since there is little literature information about this issue, the current report should provide valuable information to ECLS specialists who attempt to enroll patients that have just sustained major trauma or damage-control interventions.

As shown in Figure 2, all patients experienced an extremely hypocoagulable state soon after being connected to an ECLS circuit. The suppression of blood coagulability decayed with time and almost disappeared after 12 hours in most of the patients. This phenomenon seemed to be compatible with the pharmacodynamics of heparin. Except the initial hypocoagulability, all patients showed a decreased platelet count after 24 hours of ECLS. This platelet consumption was also found in previous studies and could be explained by an increased volume of distribution and blood-surface interaction during extracorporeal circulation $[9,13]$. Therefore we might suggest that the ECLS-associated coagulopathy was a profound hypocoagulable state induced by heparinization, hemodulition and platelet consumption [9]. This heparin-induced hypocoagulability may persist for 12 hours in adult patients with a relatively normal coagulability before VV-ECLS. From this viewpoint, reducing or even pharmacologically neutralizing the heparin content at the beginning of VV-ECLS should be helpful to attenuate the anticoagulant impact of ECLS.

In regards to the interaction between TIC and ECLSassociated coagulopathy, we had some indirect findings. As we were limited by the small number of cases, we failed to identify the correlation between TIC and the major hemorrhage during VV-ECLS, but we did find that the blood coagulability (both the intrinsic and external coagulation pathways) and the platelet counts were more suppressed in the hemorrhage group than in the non-hemorrhage group at the beginning of ECLS. Patients in the hemorrhage group also had more blood transfusions in the day before ECLS. Therefore, we may assume that these patients have a more severe TIC and are very sensitive to ECLS-associated coagulopathy, even to the heparin-minimized ECLS. The two coagulopathies may exert a synergistic effect strongly against blood coagulation and cause diffuse hemorrhages from the crushed solid organs and soft tissues. Despite there might be room for hemostasis with transfusion therapy alone, a proactive stance of surgical interventions should be taken toward major hemorrhages during ECLS. Not only because hemorrhages may reduce the efficacy of gas exchange on VV-ECLS by decreasing the pump flow rate and the amount of hemoglobin [22], but also as the transfusion therapy itself may also worsen the existed pulmonary injury.

The limitations of this study are its retrospective design and the small number of cases involved. Further prospective and collaborative studies involving large populations and an integrated protocol of coagulation measurements (such as the thrombelastogram) are necessary to optimize the analysis of the therapeutic effects of VV-ECLS.

\section{Conclusion}

VV-ECLS is an effective respiratory support in adult posttraumatic ARDS. However, the risk of major hemorrhage during VV-ECLS may be significant in patients who have just sustained major trauma and have a packed or conservatively treated hemorrhage.

\section{Additional file}

\section{Additional file 1: The integrated protocol of conventional}

mechanical ventilation and venovenous extracorporeal life support

for posttraumatic ARDS. The part of conventional ventilation was

modified from the method described in the reference [12].

\section{Competing interests}

The authors declare they have no competing interests.

\section{Authors' contributions}

MYW made substantial contributions to design the study, analyze the data, and write the manuscript. YHT, HLH, and PJL contributed to review the literature, collect the data, and design the study. CCH made substantial contributions to manuscript composition and was responsible for the final product. KCK contributed to the design of the protocol of mechanical ventilation. All authors read and approved the final manuscript.

\section{Author details}

${ }^{1}$ Department of Cardiovascular Surgery, Chang Gung Memorial Hospital and Chang Gung University, 5, Fushing Street, Gueishan Shiang, Taoyuan 333, Taiwan. ${ }^{2}$ Department of Thoracic Medicine, Chang Gung Memorial Hospital and Chang Gung University, 5, Fushing Street, Gueishan Shiang, Taoyuan 333, Taiwan. ${ }^{3}$ Department of Respiratory Therapy, Chang Gung Memorial Hospital and Chang Gung University, 5, Fushing Street, Gueishan Shiang, Taoyuan 333, Taiwan. ${ }^{4}$ Department of Clinical Pharmacy, Chang Gung Memorial Hospital and Chang Gung University, 5, Fushing Street, Gueishan Shiang, Taoyuan 333, Taiwan.

Received: 22 March 2014 Accepted: 7 September 2014 Published online: 02 October 2014

\section{References}

1. Salim A, Martin M, Constantinou C, Sangthong B, Brown C, Kasotakis G, Demetriades $D$, Belzberg $H$ : Acute respiratory distress syndrome in the 
trauma intensive care unit: Morbid but not mortal. Arch Surg 2006, 141(7):655-658.

2. Watkins TR, Nathens AB, Cooke CR, Psaty BM, Maier RV, Cuschieri J, Rubenfeld GD: Acute respiratory distress syndrome after trauma: development and validation of a predictive model. Crit Care Med 2012 40(8):2295-2303.

3. Ranieri VM, Rubenfeld GD, Thompson BT, Ferguson ND, Caldwell E, Fan E, Camporota L, Slutsky AS: Acute respiratory distress syndrome: the Berlin Definition. JAMA 2012, 307(23):2526-2533.

4. 囚: Ventilation with lower tidal volumes as compared with traditional tidal volumes for acute lung injury and the acute respiratory distress syndrome. The Acute Respiratory Distress Syndrome Network 1. N Engl J Med 2000, 342(18):1301-1308.

5. Brower RG, Lanken PN, Maclntyre N, Matthay MA, Morris A, Ancukiewicz M, Schoenfeld D, Thompson BT: Higher versus lower positive end-expiratory pressures in patients with the acute respiratory distress syndrome. N Engl J Med 2004, 351(4):327-336.

6. Gattinoni L, Carlesso E, Caironi P: Stress and strain within the lung. Curr Opin Crit Care 2012, 18(1):42-47.

7. Quilez ME, Lopez-Aguilar J, Blanch L: Organ crosstalk during acute lung injury, acute respiratory distress syndrome, and mechanical ventilation. Curr Opin Crit Care 2012, 18(1):23-28.

8. MacLaren G, Combes A, Bartlett RH: Contemporary extracorporeal membrane oxygenation for adult respiratory failure: life support in the new era 1. Intensive Care Med 2012, 38(2):210-220.

9. Esper SA, Levy JH, Waters JH, Welsby IJ: Extracorporeal membrane oxygenation in the adult: a review of anticoagulation monitoring and transfusion. Anesth Analg 2014, 118(4):731-743.

10. Paden ML, Conrad SA, Rycus PT, Thiagarajan RR: Extracorporeal Life Support Organization Registry Report 2012. ASAlO J 2013, 59(3):202-210.

11. Gando S, Sawamura A, Hayakawa M: Trauma, shock, and disseminated intravascular coagulation: lessons from the classical literature. Ann Surg 2011, 254(1):10-19.

12. Kao KC, Yang CT, Hu HC, Ting HC, Huang CT, Chou LT, Hsiao HF, Li LF, Tsai YH, Huang CC: Resolution of organ functional scores to predict the outcome in adult acute respiratory distress syndrome patients receiving high-frequency oscillatory ventilation. J Trauma 2011, 71(6):1536-1542.

13. Wu MY, Lin PJ, Tsai FC, Haung YK, Liu KS, Tsai FC: Impact of preexisting organ dysfunction on extracorporeal life support for nonpostcardiotomy cardiopulmonary failure. Resuscitation 2008, 79(1):54-60.

14. Wu MY, Lin PJ, Lee MY, Tsai FC, Chu JJ, Chang YS, Haung YK, Liu KS: Using extracorporeal life support to resuscitate adult postcardiotomy cardiogenic shock: treatment strategies and predictors of short-term and midterm survival. Resuscitation 2010, 81(9):1111-1116.

15. Tseng YH, Wu TI, Liu YC, Lin PJ, Wu MY: Venoarterial extracorporeal life support in post-traumatic shock and cardiac arrest: lessons learned. Scand I Trauma Resusc Emerg Med 2014, 22:12.

16. Johansson PI, Sorensen AM, Larsen CF, Windelov NA, Stensballe J, Perner A, Rasmussen LS, Ostrowski SR: Low hemorrhage-related mortality in trauma patients in a Level I trauma center employing transfusion packages and early thromboelastography-directed hemostatic resuscitation with plasma and platelets. Transfusion 2013, 53(12):3088-3099.

17. Khan S, Brohi K, Chana M, Raza I, Stanworth S, Gaarder C, Davenport R: Hemostatic resuscitation is neither hemostatic nor resuscitative in trauma hemorrhage. J Trauma Acute Care Surg 2014, 76(3):561-567.

18. Messai E, Bouguerra A, Harmelin G, Di LG, Cianchi G, Bonacchi M: A new formula for determining arterial oxygen saturation during venovenous extracorporeal oxygenation. Intensive Care Med 2013, 39(2):327-334.

19. Neamu RF, Martin GS: Fluid management in acute respiratory distress syndrome. Curr Opin Crit Care 2013, 19(1):24-30.

20. Ried M, Bein T, Philipp A, Muller T, Graf B, Schmid C, Zonies D, Diez C, Hofmann HS: Extracorporeal lung support in trauma patients with severe chest injury and acute lung failure: a 10-year institutional experience. Crit Care 2013, 17(3):R110.
21. Cordell-Smith JA, Roberts N, Peek GJ, Firmin RK: Traumatic lung injury treated by extracorporeal membrane oxygenation (ECMO). Injury 2006, 37(1):29-32.

22. Schmidt M: Blood oxygenation and decarboxylation determinants during venovenous ECMO for respiratory failure in adults. Intensive Care Med 2013, 39(5):838-846.

doi:10.1186/s13049-014-0056-0

Cite this article as: Wu et al:: Venovenous extracorporeal life support for posttraumatic respiratory distress syndrome in adults: the risk of major hemorrhages. Scandinavian Journal of Trauma, Resuscitation and Emergency Medicine 2014 22:56.

\section{Submit your next manuscript to BioMed Central and take full advantage of:}

- Convenient online submission

- Thorough peer review

- No space constraints or color figure charges

- Immediate publication on acceptance

- Inclusion in PubMed, CAS, Scopus and Google Scholar

- Research which is freely available for redistribution

Submit your manuscript at www.biomedcentral.com/submit
() Biomed Central 